\title{
Educação e Entretenimento ${ }^{1}$
}

\author{
Tamíris de Almeida Cutrim
}

UFF - Universidade Federal Fluminense

\section{Ceciliane Dias Gomes}

UFF - Universidade Federal Fluminense

\author{
Alexandre Farbiarz \\ UFF - Universidade Federal Fluminense
}

\begin{abstract}
Resumo
Com este trabalho, buscamos discutir e divulgar novas práticas de ensino e fomentar a produção e divulgação científica sobre Edutainment e sobre as relações discursivas na Web, com enfoque na Educação a Distância (EaD), em diferentes campos do conhecimento, contribuindo para o desenvolvimento de cursos de educação a distância na online.

Palavras chave: Jogo, Edutainment, Pedagogia.
\end{abstract}

\begin{abstract}
In this article, we discuss new teaching practices, with the purpose of disseminating scientific knowledge about Edutainment and discourse relations on the Web. With a focus on e-learning in different fields of knowledge, our larger aim is to contribute to the development of e-learning courses.
\end{abstract}

Keywords: Serious Game; Edutainment; Pedagogy.

\section{INTRODUÇÃO}

Há tempos, o Brasil vem se confrontando com sérios problemas de ensino. Desvalorização dos profissionais de educação, falta de motivação dos alunos, métodos de ensino ultrapassados e alto índice de evasão escolar, principalmente em escolas públicas, são alguns destes problemas.

\footnotetext{
${ }^{1}$ Este estudo foi desenvolvido no âmbito do grupo de pesquisas Discursos em Contextos Ciberculturais coordenado pelo prof. Dr. Alexandre Farbiarz, do curso de Comunicação Social, da Universidade Federal Fluminense.
} 
O estudo “A Crise de Audiência do Ensino Médio”, lançado em junho de 2010 pelo Instituto Unibanco e Movimento “Todos pela Educação”, aponta um dos maiores problemas existentes na educação brasileira: a evasão escolar. Segundo a pesquisa, 25\% dos adolescentes pobres, entre 15 e 17, não frequentam a escola. Em contrapartida, este índice diminui para 4\% entre os jovens considerados não pobres.

A pesquisa traçou um perfil padrão de jovem pobre e não pobre. O primeiro é caracterizado pelo sexo feminino, de cor negra, mora na região Nordeste, pertence a uma família cujo chefe é analfabeto e tem renda per capita de R\$30. Já o adolescente padrão de família não pobre é caracterizado pelo sexo masculino, de cor branca, vive na região Sul, a família possui renda per capita de \$1.000 e o responsável tem 16 anos de estudo.

Outro indicador relevante da pesquisa é que a porcentagem de jovens entre 15 e 17 anos que não frequentam a escola é sete vezes maior em famílias pobres do que nas não pobres. Os dados são de 2007 e mostram que a porcentagem dos jovens que concluíram o ensino fundamental, mas não fizeram o ensino médio, é de $7 \%$ nas famílias pobres e 1\% nas não pobres.

Ainda segundo o estudo, alguns fatores que impossibilitam os jovens de estudarem são a pobreza familiar, a necessidade de trabalhar e a dificuldade em conciliar trabalho e estudo.

Outro motivo bastante relevante que contribui para a evasão escolar é a falta de interesse dos alunos em assistir às aulas. A pesquisa "Motivos para Evasão Escolar" realizada no ano de 2006 e patrocinada pela Fundação Getulio Vargas, Fundação Educar Dpaschoal, Movimento Todos pela Educação e Instituto Unibanco, constatou que 40,3\% dos jovens de 15 a 17 anos com renda familiar acima de R\$ 100 per capita e que moram nas regiões metropolitanas de Salvador, Recife, Belo Horizonte, Rio de Janeiro, São Paulo e Porto Alegre deixam de estudar porque acreditam que a escola é desinteressante.

A falta de interesse é ainda maior entre os adolescentes de 15 a 17 anos com renda familiar inferior à $\$ 100$ per capita, chegando a 41,6\%. Outros motivos como a necessidade de trabalhar, que obteve $27 \%$ das respostas, e, em terceiro lugar, a dificuldade de acesso à escola, que aparece com 10,9\%, não superam a falta de interesse dos alunos, o principal fator que impulsiona os jovens a abandonarem a sala de aula.

O desinteresse manifestado é preocupante não só por causar a evasão escolar, mas também por provocar o baixo rendimento escolar dos jovens que estão na escola. Um 
aluno que concluiu o ensino médio, frequentando assiduamente às aulas, mas que não teve estímulo para aprender e estudar terá um rendimento muito aquém da sua capacidade de aprendizagem.

A pesquisa foi realizada com base nos suplementos de Educação das pesquisas de domicílios e empregos do Instituto Brasileiro de Geografia e Estatística (IBGE), de 2004 e 2006, utilizando as respostas de pais e alunos sobre os motivos da evasão escolar.

O estudo revela, portanto, que a falta de motivação é o principal motivo da evasão escolar. O coordenador da pesquisa, Marcelo Neri, enfatiza que, mais do que criar políticas públicas voltadas para a educação, também é preciso despertar e conquistar o interesse do jovem em permanecer na escola.

Talvez este desinteresse manifestado pelos estudantes possa ser em decorrência do modelo educacional tradicional, presente na maioria das escolas brasileiras. Este modelo se baseia no modelo de ensino difundido pelas escolas da França no século XVIII.

Segundo Mizukami (1986), na abordagem tradicional o estudante é visto como um receptor passivo de informações que lhe são oferecidas. O conhecimento tem caráter cumulativo e é adquirido por meio da transmissão, principalmente, da educação formal. A aprendizagem vincula-se a uma rotina de transmissão de conhecimentos a partir de situações de sala de aula. Para sua efetivação são utilizados métodos verbais tradicionais, como aulas expositivas com conteúdo pré-formatado. As situações são preparadas e artificiais, assim como é valorizada a recitação e exatidão na reprodução. Ocorre uma forte divisão de disciplinas e valorização de umas em detrimento de outras.

O desinteresse percebido na pesquisa decorre da baixa ação de envolvimento entre o conteúdo que está sendo ensinado e o que está sendo apreendido. No ensino da pedagogia tradicional, o estudante não é criador e construtor do seu próprio processo de aprendizagem. Em grande parte dos casos, não há um envolvimento daquilo que se pretende ensinar por parte do professor, com aquilo que se quer aprender por parte do estudante.

Paulo Freire (1970) afirma que os conteúdos didáticos são transmitidos de forma descontextualizada à realidade do educando e não propõem uma reflexão por parte dos educadores. O autor também afirma que a relação entre educador e educandos é essencialmente narradora, em que o primeiro relata suas experiências e vivências ao segundo. 
Em lugar de comunicar-se, o educador faz comunicados e depósitos que os educandos, meras incidências, recebem pacientemente, memorizam e repetem. (...) Educador e educandos se arquivam na medida em que, nesta destorcida visão da educação, não há criatividade, não há transformação, não há saber. Só existe saber na invenção, na reinvenção, na busca inquieta, impaciente, permanente, que os homens fazem no mundo, com o mundo e com os outros. (Freire, 1970:33)

Estes fatores, em conjunto, tornam a aprendizagem desinteressante e sem maior significância para os alunos que, por sua vez, são considerados, segundo o modelo de Educação Bancária defendido por Freire, como meros “recipientes”.

Deste modo, para fortalecer o vínculo do aluno com a aprendizagem é necessário outro modelo de educação. Paulo Freire propõe a educação libertadora/problematizadora como o modelo ideal a ser utilizado para a formação de alunos-cidadãos. De acordo com esta concepção, “o educador já não é o que apenas educa, mas o que, enquanto educa, é educado, em diálogo com o educando que, ao ser educado também educa” (Freire, 1970:38). Ou seja, o ato de educar é visto como algo recíproco e dual, que se fundamenta essencialmente através do diálogo, e não da imposição.

O modelo de educação problematizadora possui caráter altamente reflexivo, questionador e busca a inserção crítica dos educandos na realidade. Freire afirma que "a educação como prática da liberdade, ao contrário daquela que é prática da dominação, implica na negação do homem abstrato, isolado, solto, desligado do mundo, assim também na negação do mundo como uma realidade ausente dos homens.” (Freire, 1970: 40).

Sendo assim, a educação libertadora permite que o educando construa seu próprio conhecimento e reflita sobre o mundo a que pertence, não apenas como um mero observador, mas sim como um ser atuante, participante e transformador da realidade.

Além disso, neste tipo de educação, a autonomia do indivíduo é respeitada, visto que cada educando tem seu próprio processo de aprendizagem. Antes mesmo de ir para a escola, o jovem já traz consigo seu repertório, seu conjunto de valores, suas vivências, experiências e particularidades que o diferenciam dos outros jovens. Portanto, é natural que o aprendizado ocorra de forma distinta para cada um e não seja uma transmissão de valores e conhecimentos de um (educador) para muitos (educandos), como ocorre na educação “bancária”. 


\title{
O JOGO COMO PRÁTICA COLABORATIVA DE APRENDIZAGEM
}

Tal como nesta linha pedagógica defendida por Freire, nos jogos o indivíduo também pratica seu próprio “processo de descoberta e construção” (ALVES, 2009, p.141).

\begin{abstract}
No que refere ao cenário pedagógico, os games tornam-se espaços de aprendizagem para práticas colaborativas através de simulações marcadas por formas de pensamento não lineares que envolvem negociações e abrem caminhos para diferentes estilos cognitivos e emocionais. (Turkle apud Lynn Alves, 2006:151)
\end{abstract}

Baseado na proposta educativa Freiriana, encontramos no jogo educativo a possibilidade de um diálogo, de troca entre o educando e o conteúdo, que se explica pela própria natureza de atuação do jogo, a interatividade. No jogo, o jogador não se sente sozinho e não atua apenas como receptor do conteúdo. Ele interage com o que lhe é oferecido e está em constante oportunidade de troca, de criação, de avanços e novas modelagens.

Desse modo, o jogo pode ser um importante instrumento pedagógico, um aliado para a aprendizagem. Nele, o jogador pode supor outra forma de se relacionar com a cultura e com o conteúdo educacional. Mais que uma simples animação do fazer pedagógico (Alves, 2009:141) ou simplesmente uma forma de aprendizagem mais interativa, o jogo desenvolve diversas habilidades e competências do aluno. Lynn Alves afirma que,

Os games classificados como de simulação possibilitam aos jogadores experimentar
situações que não podem, muitas das vezes, ser concretizadas no cotidiano. Assim, através
desses jogos é possível criar novas formas de vida, gerir sistemas econômicos, constituir
famílias, enfim, simular a realidade, antecipar e planejar ações, desenvolver estratégias,
projetar conteúdos afetivos, culturais e sociais (...). (Alves, 2009:141)

Neste contexto, em que o jogo abre brechas para que os jogadores sejam criadores e descobridores e, no caso do jogo educativo, os descobridores e responsáveis pelo próprio processo de aprendizagem, abre-se a possibilidade para que o educando construa sua aprendizagem de acordo com seu ritmo e seguindo um caminho próprio, o que pedagogicamente indica um aprendizado mais efetivo e prazeroso.

Essa liberdade oferecida no jogo, eletrônico ou analógico, em que os jogadores são construtores de seu próprio percurso de aprendizagem, nos indica que nele existem 
condições que propiciam a flexibilidade e a plasticidade intelectual, em que o jogador, no seu próprio ritmo, pode avançar e retroceder de acordo com a sua vontade e a potencialidade intelectual do momento.

Para Vygotsky, (...) os jogos atuam como elementos mediadores entre o conhecimento já cristalizado, construído, presente no nível de desenvolvimento real, e nas possibilidades e potencialidades existentes na Zona de Desenvolvimento Proximal (ZDP). (ALVES, 2009: 145)

No percurso do jogo, o jogador procura explorar o cenário em que se desenrola a narrativa para decifrar, normalmente por tentativa e erro, as regras, os enigmas e a lógica do próprio jogo. Depois de descobertos os desafios propostos, o jogador procura determinar prioridades, tomar decisões e traçar estratégias para enfrentá-lo e, assim, alcançar seu objetivo.

Enquanto joga, o aluno é motivado a pensar, planejar suas ações e traçar estratégias com o intuito de encontrar um melhor caminho para resolver as situaçõesproblema que lhe são propostas. Deste modo, o raciocínio lógico, a criatividade, a atenção, a visão estratégica, a capacidade de solucionar problemas e o desejo de vencer são algumas das competências que podem ser desenvolvidas pelos jogadores.

Jogar pode ser uma atividade interessante para motivar os alunos a mobilizarem recursos e superarem desafios numa situação em que agir sem pensar, sem planejar e sem respeitar os limites não serve, não produz bons resultados, os quais ela realmente quer conquistar" (Macedo, Sícole e Norimar, 2005: 36).

Este conjunto de habilidades desenvolvidas pelos jogadores pode ser utilizado também na vida real, em situações do cotidiano.

O ambiente desperta no jogador “(...) o prazer em acompanhar o desenrolar da história construída pelos desafios propostos” (Alves, 2009:141). É justamente este prazer que torna os jogos tão atraentes para muitas crianças, jovens e adultos. A ampliação quantitativa de lançamento de jogos comerciais e o crescimento da indústria de entretenimento são decorrências disto. Segundo a ABRAGAMES, Associação Brasileira das Desenvolvedoras de Jogos Eletrônicos, somente no Brasil, a indústria de games arrecadou R \$87,5 milhões em 2008 (Manfredini et al, 2008).

O desafio é despertar este mesmo interesse e motivação também para os jogos educativos. Muitas vezes, quando aplicados na escola, os jogos educativos parecem não agradar aos alunos e nem sustentar os processos de aprendizagem da maneira que os educadores têm planejado. Isso ocorre, em grande parte dos casos, por que os jogos 
educativos são inseridos no ambiente escolar de modo “descontextualizado, ou seja, desempenhando um papel didático isolado sem que estejam articulados a uma linha pedagógica e/ou lúdica clara.” (Meira, Neves e Ramalho, 2009:2).

Portanto, como afirma Alves (2009:144), se faz necessária “a criação de espaços de ensino online que contemplem a lógica da cultura da simulação (jogos eletrônicos) em níveis de interatividade que possibilitem a construção de conhecimento, mediado pela necessária interatividade característica do processo de ensinar e aprender”.

\section{UMA EXPERIÊNCIA}

Sensíveis a esta demanda e cientes do potencial educativo dos jogos eletrônicos, os professores da Universidade Federal de Pernambuco Luciano Meira (departamento de Psicologia), André Neves (departamento de Design) e Geber Ramalho (centro de Informática) criaram em 2008 uma gincana de jogos online de cunho lúdicopedagógico. A gincana recebeu o nome de Olimpíada de Jogos Digitais e Educação (OJE) e foi desenvolvida por um consórcio de empresas do Porto Digital (Recife) para a Secretaria de Educação de Pernambuco.

Inicialmente, a OJE foi criada para atender um público-alvo formado por alunos e professores das escolas da rede pública estadual de ensino do estado de Pernambuco. Os jogos são apresentados no site www.educacao.pe.gov.br/oje, e estão divididos em enigmas, mini-jogos e jogos de realidade alternativa (ARG), cada qual com uma pontuação diferenciada, porém envolvidos dentro de um mesmo enredo. Os alunos possuem um prazo para a realização dos jogos. Os desafios abordam conteúdos didáticos do ensino médio e fundamental, com adaptações para cada nível de escolaridade, com foco nos alunos e professores do $8^{\circ}$ e $9^{\circ}$ anos do Ensino Fundamental e dos três anos do Ensino Médio. Os alunos e professores vencedores ganham prêmios especiais como consoles de games, notebooks, TVs, entre outros.

Para a elaboração da OJE, os professores da UFPE levaram em conta os seguintes critérios: produção de um ambiente lúdico e atraente; integração dos jogos entre si e destes com atividades que possam ser desenvolvidas sem o uso do computador; observação das diferenças de gênero e de ritmo de aprendizagem entre os alunos e posicionamento relevante do professor enquanto mediador. Além disso, eles também se basearam em jogos comerciais de sucesso para elaborar os mini-jogos existentes na OJE, que tem por base as matrizes oferecidas pelos Parâmetros Curriculares Nacionais (PCN). 
A Olimpíada de Jogos Digitais e Educação foi implementada como projeto piloto em 2008 para vinte escolas da região metropolitana de Recife e, em 2009, foi disponibilizada para mais de 18 mil alunos da rede pública de ensino de Pernambuco. Durante o período de execução da OJE (de maio a setembro de 2009), foi verificado que:

(...) $88 \%$ dos gestores consideraram a olimpíada uma iniciativa que aumentou o interesse dos alunos pelos estudos. Entre os professores participantes, $77 \%$ consideraram que a OJE estimulou a colaboração entre os alunos, $70 \%$ diz ter levado os enigmas para discutir em suas aulas. Entre os alunos, 68\% informaram ter aumentado o interesse pelos estudos e 41\% passaram a frequentar mais intensamente o laboratório de informática da escola. (Meira, Neves e Ramalho, 2009:6)

Em novembro de 2009, a OJE também foi implantada no estado do Rio de Janeiro. Fruto de uma parceria entre a Secretaria de Cultura e a Secretaria de Educação do Estado do Rio de Janeiro, a Olimpíada de Jogos Digitais e Educação teve a participação de 1.117 alunos e 72 professores organizados em 142 equipes de 24 escolas estaduais. A competição iniciou no dia 9 de novembro e teve a duração de, aproximadamente, um mês. Em 2010, o evento deve ser expandido para todas as escolas da rede e terá seis meses de duração, incluindo a fase classificatória e a grande final.

Qualquer aluno ou interessado em saber mais sobre esta iniciativa pode acessar os jogos da OJE através do site www.br.oje.inf.br. Logo na página inicial, o site oferece uma opção para o internauta escolher o estado em que mora. Se o estado selecionado for Pernambuco ou Rio de Janeiro (locais em que há a Olimpíada), o internauta deve escolher um desses perfis para entrar no site: Aluno, Professor, Pais e Responsáveis, Gestor ou Visitante.

Ao selecionar o perfil, a pessoa é levada à home do site que possui um layout e uma linguagem bastante jovem e de fácil acesso. Clicando no link "Inscreva-se já” aparece uma tela com algumas informações pessoais a serem preenchidas, como login e senha. Feita a inscrição, o internauta tem a opção de jogar 17 games, localizados na 


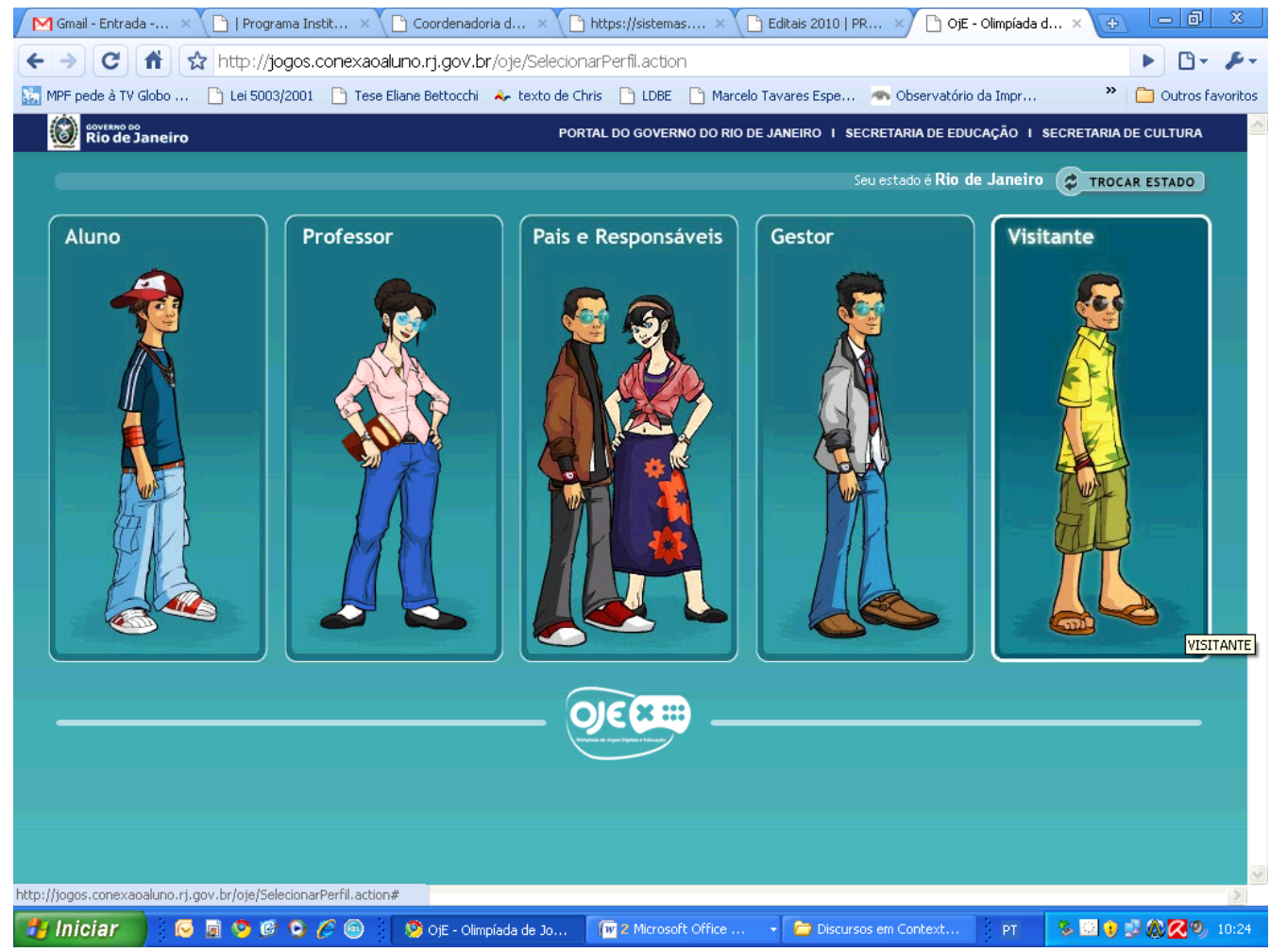

Figura 1: Página inicial do Site da OJE

lateral esquerda da tela. São eles: "Rio Limpo”, “Imuno”, "Planetários”, “Machina”, "Rock Beat”,“Corrida Contra o Tempo”, “Emaranhado”, “Flamel”, “Sr. Huh”, “Jorginaldo, "Rally Sinistro”, “Operação Anti-Mosquito”, “Tony Jones”, “Sonorus”, “Super Susto”, “Chuteira Premiada” e "Manfred”. Cada jogo possui um tutorial e no jogo “Rock Beat”, além de aparecer por escrito, também é narrado.
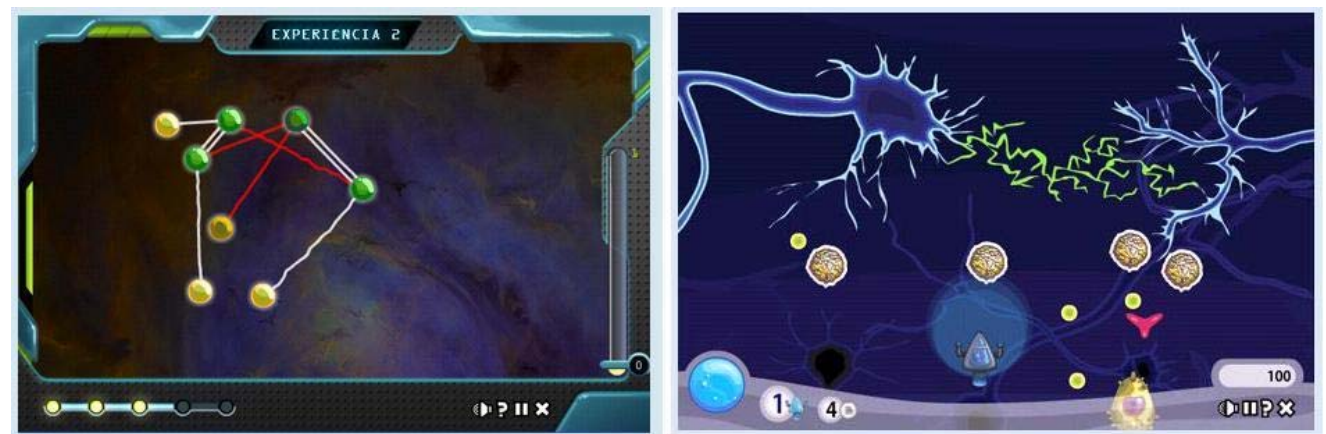

Figura 2: A figura da esquerda é do jogo chamado "Emaranhado”, no qual o jogador tem que arrastar os átomos até eles alcançarem um equilíbrio (envolve conhecimentos de Química). Já o jogo à direita é o “Imuno", no qual o jogador entra no organismo de um ser humano doente e deve combater as bactérias e elementos invasores que prejudicam à saúde (envolve conhecimentos de Biologia.) 
O site www.educacao.pe.gov.br/oje funciona como uma vitrine para mostrar e difundir os jogos e a OJE. Porém, não substitui a Olimpíada em si, de caráter educativo, e os jogos apresentados no site não necessariamente são os mesmos daqueles que compõem a gincana escolar.

A Olimpíada de Jogos Digitais e Educação é uma iniciativa recente, sobretudo no estado do Rio de Janeiro, portanto, ainda cedo para analisarmos e obtermos os resultados. No entanto, consideramos a iniciativa bastante vanguardista e encorajadora no âmbito do Edutainment (sigla em inglês para Educação + Entretenimento) e pretendemos continuar investigando esta proposta e acompanhando mais de perto seu desenvolvimento.

\section{CONSIDERAÇÕES FINAIS}

Podemos concluir com este artigo que ainda há muito que se fazer pela Educação no Brasil. Os índices de evasão escolar são bastante preocupantes e o modelo educacional presente na maior parte do nosso país não propõe ao aluno a construção e a reflexão do conteúdo transmitido em sala de aula.

Acreditamos que uma forma para contribuir para a melhora nos níveis educacionais, sobretudo diminuir os índices de evasão escolar, seria unir o Entretenimento à Educação. Muitas vezes, estes dois campos do saber são vistos por professores como antagônicos e inconciliáveis.

No entanto, através do Edutainment a aprendizagem se tornaria mais atraente e eficiente para jovens e crianças. Além disso, os recursos existentes nas novas tecnologias da informação podem promover uma aprendizagem eficaz se contextualizados a um processo didático e articulados por uma linha pedagógica bem delimitada. Eles também possibilitam estabelecer um diálogo entre os professores e seus alunos, que muitas vezes é deficitário.

A Olimpíada de Jogos e Educação possui uma proposta educacional que nos serve como referência. Segundo os resultados divulgados pelos formuladores da OJE, a partir da implementação da olimpíada nas escolas, houve um maior engajamento de alunos em um ambiente informatizado, uma maior integração entre professores e alunos, e entre os próprios alunos, além de propiciar um ambiente de aprendizagem sofisticado e inovador. 
São resultados como esses que esperamos obter em maior escala no país, fomentados através da divulgação do Edutainment e através de novas iniciativas que possuam cunho lúdico-pedagógico semelhante.

\section{AGRADECIMENTOS}

Agradecemos à Universidade Federal Fluminense (UFF), através da Pró-Reitoria de Pesquisa, Pós-Graduação e Inovação (PROPPi), assim como ao Conselho Nacional de Desenvolvimento Científico e Tecnológico (CNPq) pelo apoio à pesquisa PIBIC realizada. Agradecemos à Geber Ramalho, André Neves e Luciano Meira, da UFPE, pela permissão de pesquisa aos jogos e à bibliografia referente à Olimpíada de Jogos Digitais e Educação (OJE).

\section{REFERÊNCIAS}

Alves, L. R. G. (2009). Estratégias de jogos para EAD. In: Litto, Frederico Michael; Formiga, Marcos Maciel. (Org.). Educação à distância: o estado da Arte. São Paulo: Pearson Prentice Hall, 141-146.

Freire, P. (1970). Pedagogia do Oprimido. São Paulo: Paz e Terra.

Macedo, L.; Sícoli, A. L. \& Norimar, C. P. (2005). Os Jogos e o Lúdico na Aprendizagem Escolar. São Paulo: Artmed, 2005.

Manfredini, B. I. P. R et al. (2008). A indústria brasileira de jogos eletrônicos: Um mapeamento no crescimento do setor nos últimos 4 anos. Brasil. 2008. Disponível em < http://www.abragames.org/docs/Abragames-Pesquisa2008.pdf $>$. Último acesso em 16/08/2010.

Meira, L.; Neves, A. e Ramalho, G. (2009). Lan house na escola: uma olimpíada de jogos digitais na educação. V Seminário - jogos eletrônicos, educação e comunicação: Maceió.

Mizukami, M. da G. N. (1986). Ensino: as abordagens do processo. São Paulo: E.P.U.

Movimento Todos pela Educação. (2010). A Crise de Audiência do Ensino Médio. Grandini \& GCP Publicidade e Propaganda. Brasil.

Neri, M. (2007). Motivos da Evasão Escolar. Fundação Getulio Vargas: Rio de Janeiro.

Santos, E. \& Alves, L. (orgs.) (2006). Jogos Eletrônicos e Scrennagers: Possibilidades de desenvolvimento a aprendizagem. In Práticas pedagógicas e tecnologias digitais. Rio de Janeiro: E-papers, 145 e 151. 


\title{
OS AUTORES
}

Tamíris de Almeida Cutrim é aluna de graduação em Comunicação Social, com habilitação em Jornalismo, na Universidade Federal Fluminense e bolsista de Iniciação Científica pelo CNPq no projeto de pesquisa "Edutainment: um percurso lúdico para a aprendizagem online” na Universidade Federal Fluminense.

e-mail: tamirisdealmeida@gmail.com

Ceciliane Dias Gomes é graduanda em Pedagogia na Faculdade de Educação da Universidade Federal Fluminense

e-mail: cissadonahi@hotmail.com

\begin{abstract}
Alexandre Farbiarz é Doutor em Design pela PUC-Rio, Mestre em Educação e Linguagem pela USP e Mestre em Design pela PUC-Rio. Professor Adjunto do Departamento de Comunicação Social da Universidade Federal Fluminense - na área de ênfase em Design Editorial; Coordenador do Grupo de Pesquisa no CNPq Sujeitos, linguagens e suportes em contextos ciberculturais.

e-mail: alexfarbiarz@terra.com.br
\end{abstract}

